\title{
Healthcare, artificial intelligence and the Fourth Industrial Revolution: Ethical, social and legal considerations
}

\author{
S Mahomed, BCom, LLB, LLM, PhD \\ Department of Jurisprudence, School of Law, University of South Africa, Pretoria
}

Corresponding author: S Mahomed (mahoms1@unisa.ac.za)

\begin{abstract}
Artificial intelligence (Al) is usually associated with high-tech robotics, automation and science fiction, and can seem daunting to some. However, Al in general has grown considerably over the past 50 years, and is the current driving force behind the Fourth Industrial Revolution. While it proposes improvements to almost every field that it touches, including the medical sciences, ethical, social and legal challenges associated with its implementation arise. One may question whether Al, which can replace the human element by nature of its operation, has a place in South African and African communities, in certain instances. Al systems can potentially become discriminatory and lead to stigmatisation, if the systems are not properly tailored to reflect the specific characteristics of a population group. Over-reliance on the use of technology, without fully understanding the effects and consequences of the systems, could also prove to be problematic.
\end{abstract}

S Afr J Bioethics Law 2018;11(2):93-95. DOI:10.7196/SAJBL.2018.v11i2.664

We find ourselves in an era where 'cutting-edge' technology is at the forefront of almost every industry. However, a general fear of the unknown is prevalent when we are confronted with new, unfamiliar technologies. The same applies when one considers artificial intelligence (Al). Al is usually associated with high-tech robotics, automation and science fiction, and can seem daunting to some. Nevertheless, Al proposes improvements to almost every field that it touches, including the medical sciences. The benefits of Al have been deliberated extensively in medical literature. ${ }^{[1]} \mathrm{Al}$ offers medical professionals an opportunity to recognise and diagnose diseases more efficiently, and to provide treatment that is more effective to patients. In the developing-world healthcare setting, Al provides the promise of insight and hope for medicine, in that it offers alternative solutions to communities where trained doctors and resources are scarce. ${ }^{[2]}$ The purpose of this article is to briefly address the impact and importance of $\mathrm{Al}$ in the healthcare setting, and to raise concerns about some of the ethical, social and legal challenges that could arise with its implementation in the African context.

The Nuffield Council Briefing Note on Al in healthcare and research (the briefing note) asserts that there is no universally accepted definition of $\mathrm{Al}^{\left[{ }^{[3]}\right.}$ The briefing note indicates that the term broadly refers to 'computing technologies that resemble processes associated with human intelligence, such as reasoning, learning and adaptation, sensory understanding, and interaction. ${ }^{\left[{ }^{[3]}\right.} \mathrm{Al}$ has also been defined as 'the encompassing name for all research that aims to develop machines (e.g. computers, robots, embedded devices) with similar types of intelligent behaviour [as that] exhibited by humans. These aspects of intelligence include solving tasks, forming plans, abstract reasoning, using memory of past events to influence future decisions and the use of language, among others. ${ }^{[4]} \mathrm{Al}$ in medicine is certainly not a new notion, and dates as far back as the 1970s. ${ }^{[5]}$ However, the field of $\mathrm{Al}$ in general has grown considerably over the past 50 years, and is the current driving force behind the Fourth Industrial Revolution.

The First Industrial Revolution took place towards the latter part of the 18th century when advancements in machinery, steam power and iron production, along with a new type of energy (due to extraction of coal and the invention of the steam engine) were witnessed. Although it aimed to replace agriculture with industry, the key resource remained human labour, which was assisted by machinery. The latter part of the 19th century saw the Second Industrial Revolution unfold, with new technological advancements in the chemical, electrical, oil, steel and plastic industries. The Second Industrial Revolution focused on developing publically funded, centralised facilities for education and scientific research, which focus was amplified in the Third Industrial Revolution. ${ }^{[6]}$ The Second Industrial Revolution transformed communication and transport, and saw the creation of the automobile and the aeroplane. It also initiated the use of electrical power to drive mass production. ${ }^{[7,8]}$ The Third Industrial Revolution emerged in the latter part of the 20th century, and witnessed the emergence of information technology, biotechnology, nuclear energy and electronics to automate production. We are now observing the Fourth Industrial Revolution, which is described as the 'advent of cyber-physical systems ${ }^{\left[{ }^{[9]}\right.}$ that involve novel competencies for humans and machines. This includes the development of genome-editing techniques, and new forms of machine intelligence. According to Schwab: 'It is characterised by a fusion of technologies that is blurring the lines between the physical, digital and biological spheres. ${ }^{[8]}$ It is submitted that this blurring of lines adds to the ethical, social and legal complexities that must be considered when the use of $\mathrm{Al}$ in medicine is contemplated.

The financial consequences of $\mathrm{Al}$ cannot be underestimated, as global economic returns in this field are predicted to be in the region of USD16 trillion. ${ }^{[10]}$ Currently, Al is being used to assist the decision-making 
processes in public health supply chains in developing countries, as well as to improve access to medications for patients. ${ }^{[1]]}$ The advantages of Al in the healthcare setting are numerous. It can assist with managing large-scale data collection processes, and with the interpretation of the information collected. Al is also able to use complex algorithms to learn features from large volumes of data, which will assist clinicians and aid medical research. ${ }^{[1]} \mathrm{Al}$ can prioritise care for patients in accordance with different needs; offer cost-cutting measures; provide predictive analytics for more serious medical conditions, which could then assist healthcare providers in being proactive rather than reactive; and ensure that healthcare facilities have the necessary supplies, which, in turn, should improve patient access to potentially life-saving medicines. An Al system can also assist physicians by storing and locating relevant and current medical information from journals, textbooks and clinical practices, which in turn could inform patient care. ${ }^{[1,12]}$ It is also argued that because the human element is removed from its functioning, Al can prevent 'human error' from occurring in clinical practice. ${ }^{[1,2]}$ With the imminent adoption of a National Health Insurance system, medical professionals leaving South Africa $(\mathrm{SA})$ at an alarming rate, ${ }^{[13]}$ and a large percentage of those medical professionals who do remain in SA choosing not to work for the state, ${ }^{[14]}$ implementing Al into our healthcare system could work to SA's advantage, allowing for a more effective healthcare structure, and improved access for our vulnerable population groups.

From discussions around Al-assisted robotic surgery and virtual nursing assistants, to assistance with workflow, diagnoses and image analysis, ${ }^{[15]}$ the possibilities for $\mathrm{Al}$ in the practice of healthcare and medical research seem endless. Nevertheless, the ethical, legal and social issues associated with its implementation in Africa, considering the continent's diversity, have not yet been adequately addressed.

\section{Removing the human element}

While the hype around the positive effects of $\mathrm{Al}$ is gaining momentum, it is important to consider that African societies are communityorientated, with African philosophical concepts recognising 'humanism' as linking the individual to the collective through a 'brotherhood' or 'sisterhood'! ${ }^{16]}$ According to Behrens, 'Perhaps the most significant salient African moral perspective is the importance of community. ${ }^{[17]}$ One may therefore question whether Al, which can replace the human element by nature of its operation, has a place in SA and African communities, especially in certain instances. For example, substituting the human element in the practice of healthcare may lead to situations of social isolation, if Al replaces the practitioner's role entirely. Patients often confide in their healthcare practitioners, and view them as sounding boards, placing a great deal of trust in them. In addition, practitioners are able to show empathy, compassion and care, and may pick up certain psychological symptoms in their patients which an Al device may not be able to detect. On the other hand, there may be advantages to replacing the human element; e.g., Al, in the form of IBM's Watson (IBM Corp., USA), a question-answering computer program that is able to converse with humans, is already being piloted in over 6000 facilities across Kenya, primarily to assist with stock shortages and supply-chain issues. Patients and practitioners are able to engage the program through various means (SMS, voice notes and online messaging services), and ask questions related to current stock of medications, including when more stock of a specific drug will be ordered and available for use. The Al also provides advice regarding what to do when medication expires, how to dispose of medical waste and how to treat minor injuries. ${ }^{[18]}$

Debates surrounding the moral status of artificial agents as human persons are growing and developing. ${ }^{[19]}$ However, interacting with an Al device, while beneficial in terms of providing empowerment and independence to the patient, should not aim to replace human interaction entirely. In addition, an erosion of the trust relationship between the patient and the healthcare practitioner may result should an Al device assist with a diagnosis, or provide information related to the patient that the healthcare practitioner is unable to adequately explain. It could also undermine the competence of the practitioner, who may have years of clinical experience behind him/her. Furthermore, the question of how the practitioner would exercise his/her ethical duty towards the patient must also be considered, especially where there are wider interests at stake.

\section{Data bias and security}

Although it is argued that Al can reduce 'human error' from occurring when analysing data, concerns have been raised that Al systems can potentially become discriminatory, and lead to subsequent stigmatisation, if the systems are not properly tailored to reflect the specific characteristics of a population group ${ }^{[3]} \mathrm{Al}$ systems could contain algorithms that reflect the prejudices and specific beliefs of the creators of the Al systems, which could in turn generate results that reflect these prejudices and beliefs. ${ }^{[20]}$ With privacy breaches in respect of healthcare data continually being placed in the spotlight, ${ }^{[21]}$ added complexities around the safety of data contained within or generated from the Al system come into question. There is potential for the Al system itself to be hacked, manipulated or spammed with 'fake' data, which could become problematic if not detected in time. Concerns have also been raised that Al may not be used for its intended purpose. While Al should be used for good, it could be manipulated and used maliciously. For example, Al could be used to reveal sensitive information about a person's health without them knowing, or be used to conduct cyber attacks on a large scale. ${ }^{[3]}$

\section{Quality control}

If $\mathrm{Al}$ is used to make diagnoses, control certain equipment and provide advice to a patient, we may be treading a very thin line, by finding ourselves over-reliant on the use of technology without fully understanding the effects and consequences of the system. This, in turn, could result in complexities in respect of quality control when a healthcare practitioner is removed from the process of rendering a healthcare service. Should an Al system make an error, this could have serious implications for the practitioner, patients and institution involved. A devastating example of the negative effects of over-reliance on technology is illustrated by the infamous Therac-25 scandal. This device, dubbed the 'cancer-zapper', which, upon investigation, was found to contain defective software, resulted in the death of four patients, and left two others with lifelong injuries. In addition, the machine was designed in such a way that it relied heavily on the controlling computer for safety. ${ }^{[22]}$

\section{Legal and policy complexities}

Currently, SA does not have a legal framework in place around the governance of Al. As in most instances, the law tends to lag behind scientific and technological developments. Since many of the 
complexities raised above overlap with the issues around the use of data, it is prudent to consider what our current laws on data protection provide in this regard. The Protection of Personal Information Act (POPI) No. 4 of $2013,{ }^{[23]}$ in section $71(1)$, specifically states that a data subject 'may not be subject to a decision which results in legal consequences for him, her or it, or which affects him, her or it to a substantial degree, which is based solely on the basis of the automated processing of personal information intended to provide a profile of such person, including his or her performance at work, or his, her or its credit worthiness, reliability, location, health, personal preferences or conduct.' This essentially means that a person or institution (data subject) may not be subjected to an automated decision based on a personality profile, unless (and in accordance with 71(2) of POPI) the automated decision-making is allowed for the purposes of concluding a contract, provided the request of the data subject in terms of the contract has been met, or appropriate measures have been taken to protect the data subject's lawful interests, or, the decision is governed by a code of conduct in which appropriate measures are laid down for protecting the lawful interests of data subjects. ${ }^{[24]}$ In addition, the uncertainty as to who is actually in control when the use of $\mathrm{Al}$ in healthcare is contemplated is a reality. This would then have implications for a patient's legal recourse should a private healthcare practitioner, the state or the creator of the Al device be held liable for an $\mathrm{Al}$ error, if one occurs. Furthermore, regulatory policies and guidelines would have to be updated in terms of the Health Professions Council of SA and other similar statutory councils. Moreover, other pertinent laws would require amending, and perhaps even new laws enacted, to address the legal hiatus in this regard.

\section{Conclusion}

There is no universally accepted definition of Al. Neither is there consensus globally on whether it is still in its infancy, or has moved beyond this stage. However, there is no denying that $\mathrm{Al}$, as the driving force behind the Fourth Industrial Revolution, will have a positive impact on the future of medicine, especially in developingworld settings, where resources are scarce. But the excitement around Al must be balanced with broader ethical, legal and social concerns when its use in medicine is contemplated. Furthermore, there are issues specific to an African context which should be addressed and incorporated into a concise governance framework. According to Stephen Hawking, 'Artificial intelligence is likely to be either the best or worst thing to happen to humanity. ${ }^{\text {!25] Without }}$ careful consideration of the ethical and social implications for our communities, in addition to navigating this terrain in the absence of a regulatory framework, we may find ourselves on the brink of a revolt, rather than a revolution that could be of benefit to mankind.

Acknowledgments. None.

Author contributions. Sole author.

Funding. None.

Conflicts of interest. None.

1. Jiang $F$, Jiang $Y$, Zhi $H$, et al. Artificial intelligence in healthcare: Past, present and future. Stroke Vasc Neurol 2017;2(4):230-243. https://doi.org/10.1136/svn-2017000101
2. Olk S. Al in African healthcare revolutionising the industry. https:// borgenproject.org/ai-in-african-healthcare-revolutionizing-the-industry/ (accessed 8 November 2018).

3. The Nuffield Council on Bioethics. Artificial intelligence (AI) in healthcare and research. http://nuffieldbioethics.org/project/briefing-notes/artificialintelligence-ai-healthcare-research (accessed 8 November 2018).

4. University of Stellenbosch Deep Learning Indaba. Artificial intelligence in Africa promoted with Deep Learning Indaba conference. http://www.sun.ac.za/ english/Lists/news/DispForm.aspx?ID=5904 (accessed 8 November 2018).

5. Patel VL, Shortliffe EH, Stefanelli $M$, et al. The coming of age of artificial intelligence in medicine. Artif Intell Med 2009;46(1):5-17. https://doi.org/10.1016/j. artmed.2008.07.017

6. Von Tunzelmann N. Historical coevolution of governance and technology in the industrial revolutions. Struct Change Econ Dynamics 2003;14(4):365-384. https:// doi.org/10.1016/S0954-349X(03)00029-8

7. Sentryo. The 4 industrial revolutions. https://www.sentryo.net/the-4-industrialrevolutions/ (accessed 8 November 2018).

8. Schwab K. The Fourth Industrial Revolution: What it means and how to respond. https://www.weforum.org/agenda/2016/01/the-fourth-industrial-revolutionwhat-it-means-and-how-to-respond/ (accessed 8 November 2018).

9. Davis N. What is the Fourth Industrial Revolution? https://www.weforum org/agenda/2016/01/what-is-the-fourth-industrial-revolution/ (accessed 8 November 2018).

10. Hoosen Z. How Africa can embrace an Al-enabled future. https://www.africa. com/how-africa-can-embrace-an-ai-enabled-future/ (accessed 8 November 2018).

11. Creamer Media's Engineering News. Artificial intelligence is solving African healthcare challenges. http://www.engineeringnews.co.za/article/artificialntelligence-is-solving-african-healthcare-challenges-2018-07-20/rep id:4136 (accessed 8 November 2018).

12. DiSanzo D. Watson Health is committed to using Al to tackle major healthcare challenges. https://www.ibm.com/blogs/watson-health/ai-healthcare-challenges/ (accessed 8 November 2018)

13. Van der Spuy Z, Zabow T. Money isn't everything - CMSA doctor survey shows some noteworthy results. S Afr Med J 2017;107(7):550-551. https://doi. org/10.7196/SAMJ.2017.v107i7.12643

14. Brits E. SA health sector faces a crisis. https://www.news24.com/SouthAfrica/ News/sa-health-sector-faces-a-crisis-20161008 (accessed 8 November 2018).

15. Marr B. Powerful real-world examples that show the latest advances. https://www. forbes.com/sites/bernardmarr/2018/07/27/how-is-ai-used-in-healthcare-5powerful-real-world-examples-that-show-the-latest-advances/\#46a139d25dfb (accessed 8 November 2018).

16. Swanson DM. Ubuntu: An African contribution to (re)search for/with a 'humble togetherness'. J Contemp Issues Educ 2007;2(2):53-67. https://doi.org/10.20355/ C5PP4X

17. Behrens KG. Towards an indigenous African bioethics. S Afr J Bioethics Law 2013;6(1):32-35. https://doi.org/10.7196/SAJBL.255

18. Averda. Artificial intelligence could solve Africa's healthcare logistics issues. http://averda.co.za/news/artificial-intelligence-solve-africas-healthcarelogistics-issues/ (accessed 8 November 2018).

19. Wareham C. On the moral equality of artificial agents. Int J Technoethics 2011;2(1):35-42. https://doi/org/10.4018/jte.2011010103

20. UK Parliament. House of Lords Select Committee on Artificial Intelligence, Collated Written Evidence Volume. https://www.parliament.uk/business/ committees/committees-a-z/lords-select/ai-committee/publications/ (accessed 8 November 2018)

21. Kupwade Patil H, Seshadri R. Big data security and privacy issues in healthcare IEEE International Congress on Big Data, Anchorage, AK, 2014:762-765. https:// doi/org/10.1109/BigData.Congress.2014.112

22. Leveson NG, Turner CS. An investigation of the Therac- 25 accidents. Compute 1993;26(7):18-41.

23. South Africa. Protection of Personal Information Act No. 4 of 2013.

24. Roos A. Data protection law in South Africa. In: African Data Privacy Laws, Laws Governance and Technology Series 33. Makulilo AB (ed). Springer Cham Germany,2016:189-227

25. Hawking S. 'Artificial intelligence is likely to be either the best or worst thing to happen to humanity.' https://www.theguardian.com/science/2016/ oct/19/stephen-hawking-ai-best-or-worst-thing-for-humanity-cambridge (accessed 11November 2018).

Accepted 12 November 2018 